\title{
HORMONE-DEPENDENT AND HORMONE-INDEPENDENT CONTROL OF METABOLIC AND DEVELOPMENTAL FUNCTIONS OF MALATE DEHYDROGENASE - REVIEW
}

\author{
Peter Daniš, Robert Farkas \\ Laboratory of Developmental Genetics, Institute of Experimental Endocrinology, Slovak Academy of Sciences, 83306 \\ Bratislava, Slovakia \\ e-mail: ueenfark@savba.sk
}

\begin{abstract}
Malate dehydrogenases (MDHs) are specific class of ubiquitous and multimeric oxidative decarboxylases with well conserved amino acid sequences in structurally important regions and with similar overall structural topology. They mostly use malate or oxaloacetate as substrates to generate pyruvate and utilize preferentially NADP or NAD as cofactor. Among species and even within an organism they differ in their subcellular localization and specificity for the cofactor. Comparison across microbial, plant and animal kingdoms show that MDHs were able to adopt tissue-, species- or environmental-specific functions while still keeping main structural features. Although basic principles of MDH regulation are similar to other enzymes and include oligomerization, cofactor binding, divalent cation availability, some of MDH enzymes are regulated also at different levels involving control of hysteresis, protein-protein interaction and gene expression. In this review we concentrate on those aspects of MDH function and regulation in animals that are specifically associated with cell differentiation and proliferation, ontogenic development, hormonal control, and partly with diseases. Accenting these aspects of MDHs provides emerging and new views on their regulatory function in complex eukaryotic metazoan organisms that goes beyond their classical role in basic metabolism.
\end{abstract}

\section{Introduction}

Malate dehydrogenases, or MDHs (EC 1.1.1.37/EC 1.1.1.38/EC 1.1.1.39), constitute a family of evolutionarily very old and ubiquitous multimeric enzymes that reversibly catalyze the conversion of oxaloacetate and malate into pyruvate, and that differ in their subcellular localization and specificity for the cofactor. The cytosolic MDHs (L-malate:NADP ${ }^{+}$oxaloacetate-decarboxylating oxidoreductase; EC 1.1.1.40), also known as NADP-malic enzymes (ME), catalyze the NADPdependent oxidative decarboxylation of malate into pyruvate and carbon dioxide to generate NADPH. Due

Corresponding author: Dr. Robert Farkaš, Institute of Experimental Endocrinology, Slovak Academy of Sciences, Vlárska 3, 83306 Bratislava, Slovakia, Phone: +421-2.-5477-3800, ext. 216; Fax: +421-2-5477-4247; e-mail: ueenfark@savba.sk to its ability to produce NADPH, ME is thought to be a key enzyme in lipid biosynthesis. Comparison of phylogenetically distant MDHs reveals a relatively low degree of sequence similarity. However, several residues located in motifs and domains critical for substrate recognition, catalysis, cofactor binding and subunit interface are highly conserved (TRIPATHI 1993; GowARD and NichOlLs 1994; GoODRIDGe et al., 1996; HiLl et al., 1996; Escher and WidMer 1997; MCAlisTER-HENn and SMALl 1997). Eukaryotic ME is found in both vertebrates and invertebrates as well as in plants. These enzymes require $\mathrm{Mg}^{2+}$ or $\mathrm{Mn}^{2+}$ for their activity and also display a high specificity and low $\mathrm{Km}$ for $\mathrm{NADP}^{+}$. At least for MDHs of the EC 1.1.1.37 family of enzymes it is known that they catalyze the conversion of oxaloacetate and malate, and this reaction is coupled with easily detectable cofactor oxidation/reduction. The MDHs are ubiquitous enzymes displaying several isoforms, for which several isoforms have 
been identified, differing which differ in their subcellular localization and specificity for the cofactor NAD or NADP (GIETL 1992a).

Organelle-targeted malate dehydrogenases (mitochondrial, peroxisomal, chloroplast, and glyoxysomal) are synthesized with 25-55 amino terminal extension that is cleaved off in connection with the import of the enzyme precursor into the organelle (GIETL 1992b). Several of these organelle-specific malate dehydrogenases are remarkably similar with respect to their kinetic properties, but differ widely in other characteristics, e.g. molecular weight (MW), isoelectric point (pI), thermostability and serological properties (Hock and GIETL 1982). Although not regular, but several MDHs display competitive affinity for two different cofactors. For example, some animal as well as plant NADP-malic enzymes were shown to possess intrinsic NAD-dependent malic enzyme activity. The NAD-dependent activity is competitively inhibited by micromolar concentrations of NADP and NADPH, reflecting the high affinity of malic enzyme for $\mathrm{NADP}(\mathrm{H})$. Several observations on these enzymes indicate that the NAD- and NADP-dependent activities are likely catalyzed by the same active site. Manipulating divalent cations and the use of NAD as an alternating coenzyme have revealed interaction between the binding of coenzyme and metal ions and their effects on the Km values of each of the other participants in the malic enzyme reaction. The affinity of malic enzyme for the divalent metal ions like $\mathrm{Mg}^{2+}$ and particularly $\mathrm{Mn}^{2+}$ or even for alternative substrate was also shown do be dependent on the nucleotide coenzyme. In turn, the divalent metal ion influences the affinity of the enzyme for the coenzyme as well as substrate (AsHTON 1997).

In general our present knowledge about MDH proteins reflects past interest in their role in basic metabolism with special emphasis on cytosolic-mitochondrial metabolite shuttling, indirect control of tricarboxylic acid (TCA) cycle, involvement in glycolytic and oxidative pathways, and lipogenesis. These aspects are discussed in detail in several reviews (GIETL 1992a; TriPATHI 1993; GowARD and Nicholls 1994; HiLl et al., 1996; McAlister-Henn and Small 1997; Musrati et al., 1998; MEvARECH et al., 2000; Drincovich et al., 2001; Marhuenda-Egea and Bonete 2002; Minarik et al., 2002; TEHEI and ZACCAI 2005) which we recommend to the attention of interested readers. In spite of the fact that some of the MDHs are able to respond to imbalanced physiological conditions by changes in enzyme activity and could also serve as potential differential diagnostic tools, surprisingly there is limited knowledge on misfunctioning MDHs in diseases or adverse physiological conditions. One of the reasons why it is so may be extreme sensitivity of the organism to altered (mutated) or simply misfunctional MDH and, therefore, most of such a mutational changes in $\mathrm{MDH}$ enzymes were eliminated by selection pressure due to their lethal consequences. Based on some recent data and results that have not been in the centre of the views, here we would like to accent several aspects of MDH function that go beyond the basic metabolism and deal with their potential role in cell differentiation and ontogenic development thus providing emerging and new views on their regulatory function in eukaryotic metazoan organisms.

\section{Differentiations state-specific and disease- related functions of $\mathrm{MDHs}$}

There are several indications that malate dehydrogenases may reflect growth phase or differentiation state of a particular tissue. For example, insulin-induced early growth phase in hepatic cells is accompanied by shortterm repression of cytosolic ME (BARROSO and SANTISTEBAN 1999). Growth phase and differentiation state of cells is particularly well studied in malignancies and transformed cells. It has been found that poorly differentiated malignant cells show high aerobic glycolysis. Also other metabolic ways are deficient, as for example, intramitochondrial aldehyde catabolism, at the origin of a possible acetaldehyde toxicity, which can be circumvented by the synthesis of an unusual and neutral product for mammalian cells acetoin, through tumoral pyruvate dehydrogenase. If most of the glycolytic pyruvate is deviated to lactate production, little of the remaining carbons enter a truncated Krebs cycle where citrate is preferentially extruded to the cytosol where it feeds sterol synthesis. Glutamine is the major oxidizable substrate by many tumor cells. Inside the mitochondrion, it is deaminated to glutamate through a phosphate-dependent glutaminase (BAGGETTO 1992). Under these conditions, glutamate is preferentially transaminated to $\alpha$-ketoglutarate that enters the Krebs cycle. Glutamine may be completely oxidized through the abnormal Krebs cycle only if a way of forming acetyl CoA is present: cytosolic malate entering mitochondria is preferentially oxidized to pyruvate and $\mathrm{CO}_{2}$ through an intramitochondrial $\mathrm{NAD}(\mathrm{P})^{+}$-malic enzyme (ME), whereas intramitochondrial malate is preferentially oxidized to oxaloacetate through malate dehydro- 
genase, thus providing a high level of intramitochondrial substrate compartmentation (BAGGETTO 1992). These observations indicated that described and perhaps many other regulatory aberrations in tumor cells appear to be reflections of a complex set of non-random phenotypic changes, caused by misexpression of oncogenes and/or oncogene-driven genes. Although not a primary cause, several of these metabolic aberrations could serve as diagnostic marker in some types of cancer and other diseases.

When analyzing mitochondrial and cytosolic $\mathrm{NADP}^{+}$- and $\mathrm{NAD}^{+}$-dependent malic enzymes in several human tumor cell lines it became evident that both mitochondrial and cytosolic $\mathrm{NADP}^{+}-\mathrm{ME}$ have significantly increased activity (BALINSKY et al., 1983, 1984; LOEBER et al., 1994). On the other hand, earlier studies suggested that the deficiency of cytosolic ME is a possible marker for malignancy in lymphoid cells (Povey et al., 1981). This conclusion cannot be extended to tumor cells derived from tissues of epithelial origin, since all carcinoma cell lines studied so far have considerable $\mathrm{NADP}^{+}-\mathrm{ME}$ activities. An extended study investigating the status of the different MEs in a large number of human cell lines has shown that no mitochondrial NADP ${ }^{+}-\mathrm{ME}$ was found in the tumor cell lines tested. This finding differs from a report of an increase in mitochondrial $\mathrm{NADP}^{+}-\mathrm{ME}$ of preneoplastic and tumor-derived rat tracheal cells when compared to corresponding normal primary cells (WASILENKO and MARCHOK 1985). However, it is possible that this reported increase in $\mathrm{NADP}^{+}-\mathrm{ME}$ activity reflected mitochondrial $\mathrm{NAD}^{+}-\mathrm{ME}$ since, in contrast to the human $\mathrm{NAD}^{+}-\mathrm{ME}$ which is hardly active with $\mathrm{NADP}^{+}\left(\mathrm{S}_{\mathrm{AUER}}\right.$ and DAUCHY 1978; SAUER et al., 1980), rat NAD+-ME has significant activity when assayed with $\mathrm{NADP}^{+}$(SAUER and DAUCHY 1978; LOEBER et al., 1991). By contrast, breast cancer tumour cells show reduced activity in mitochondrial ME (PERUMAL et al., 2005) which was often characterized as pI 7.8 isoform (MAZUREK et al., 1996, 1998, Caetano et al., 1997).

Several studies have proved that the cytosolic $\mathrm{NADP}^{+}-\mathrm{ME}$ expressed in the tumor cells is the same as the $\mathrm{ME}$ expressed in normal liver and adipose tissue (SAuer and Dauchy 1978; Loeber et al., 1991). Posttranslational modifications specific for tumor cells affecting the activity of the protein are unlikely since the recombinant $\mathrm{ME}$ has the same size, as seen in SDSpolyacrylamide gels. In normal tissues, cytosolic ME provides NADPH for fatty acid biosynthesis. However, it has been found that the NADPH production by
ME was small when compared to glucose-6-phosphate dehydrogenase or NADP'-dependent isocitrate dehydrogenase the activity of which is about $50 \%$ cytosolic (SAUER and DAUChy 1978; Loeber et al., 1991; NoguCHI et al., 1993). It is unlikely that cytosolic ME contributes significantly to the NADPH pool in the cytoplasm of the tumor cells. It is more likely that pyruvate is the relevant product of the ME reaction in tumor cells.

In transformed oval liver epithelial cells that proliferate during the early stages of hepatocarcinogenesis, a strong correlation between the glycolytic flux rate and glutamine consumption as well as glutamate production was observed. Furthermore, the transport of glycolytic hydrogen, produced by the glyceraldehyde 3phosphate dehydrogenase-catalyzed reaction, from the cytosol into the mitochondria by means of the malateaspartate shuttle was enhanced, due to alterations in the activities of malate dehydrogenase and glutamate oxaloacetate transaminase. The upregulation of the glycolytic hydrogen transport and the alterations in the glycolytic enzyme complex led to an enhanced pyruvate production at high glycolytic flux rates, thus affecting cytosolic malate dehydrogenase activity at the level of end product (MAZurEK et al., 1999). This indicated that a special metabolic feature, in this case increased glycolysis and glutaminolysis, is characteristic for tumor cells.

Human cytosolic malate dehydrogenase (so-called MDH1) is important in transporting NADH equivalents across the mitochondrial membrane, controlling tricarboxylic acid (TCA) cycle pool size and providing contractile function. Cellular localization studies indicate that MDH1 mRNA expression has a strong tissue-specific distribution, being expressed primarily in cardiac and skeletal muscle and in the brain, at intermediate levels in the spleen, kidney, intestine, liver, and testes and at low levels in lung and bone marrow (Lo et al., 2005). The variety of MDH functions are primarily related to aerobic energy production for muscle contraction, neuronal signal transmission, absorption/resorption functions, collagen-supporting functions, phagocytosis of dead cells, and processes related to gas exchange and cell division. During neonatal development, MDH1 is expressed in human embryonic heart as early as the 3rd month and then become upregulated from the 5th month until the birth. The expression of MDH1 is maintained in the adult heart but is not present in levels as high as in the fetus. Interestingly, highly overexpressed levels of MDH1 are found in left ventricular cardiac muscle of dilated cardiomyopathy 
(DCM) patients when contrasted to the diseased nonDCM and normal heart muscle by in situ hybridization and Western blot. These observations indicate that changes in MDH1 activity or expression appears to be related to activation of glucose oxidation in relatively hypoxic environments of fetal and hypertrophied myocardium (Lo et al., 2005). Very recent studies of Yoon et al. (2006) demonstrated that mammalian cytosolic malate dehydrogenase named Mor2 plays even more crucial role in mice oocyte maturation and embryo development. Silencing Mor2 function by RNA interference in germinal vesicle- and metaphase I (MI)-arrested oocytes has greatly decreased oocyte maturation as well are the rate of blastocyst development. Thus, cytosolic MDH is an essential factor for oocyte maturation and embryo development in mouse most probably by providing NADH and controlling TCA cycle (YoON et al., 2006).

The significance of mitochondrial $\mathrm{NAD}^{+}-\mathrm{ME}$ is thought to be related to the use of glutamine as a respiratory fuel, in a pathway from glutamine to lactate that has been named glutaminolysis (McKeEHAN 1982). This pathway not only provides energy by using a truncated Krebs cycle from $\alpha$-ketoglutarate to malate, it also produces intermediates for anabolic purposes in tumor cells, e.g. aspartate and nitrogen groups for DNA biosynthesis. Malate generated from glutamine in the mitochondria has three possible options: conversion to oxaloacetate by malate dehydrogenase, decarboxylation to pyruvate in the mitochondria by $\mathrm{NAD}^{+}-\mathrm{ME}$, or transport into the cytoplasm. Here, malate can be decarboxylated by cytosolic ME with subsequent conversion to lactate by lactate dehydrogenase. $\mathrm{NAD}^{+}$produced by this reaction can be used by glyceraldehyde3-phosphate dehydrogenase, thus compensating for the expression of a partially inactive pyruvate kinase in tumor cells (EIGENBRODT et al., 1992). A significant proportion of glutamine taken up by tumor cells and lymphocytes ends up in lactate, which is secreted (McKEEHAN 1982; Eigenbrodt et al., 1985; Brand et al., 1989). Therefore, a possible function of the cytosolic NADP ${ }^{+}$ -ME in tumor cells is the conversion of excess mitochondrial malate, which can cross the mitochondrial membrane readily, to pyruvate, which is subsequently converted to lactate and extruded from the tumor cell.

It is becoming well established (more evident) that alterations in the activities of enzymes related to energy metabolism (WASHIZU et al., 2005) in malignant cells or cells undergoing the process of transformation are due to alterations in the regulation of mitochondrial and cytosolic MDHs, cytosolic lactate dehydrogenase (LDH) and often also pyruvate kinase (PK). In many cases this process leading to changes in energy metabolism is started by misregulation of one or few genes coding for enzymes participating in TCA or closely related metabolic cycle (RAO et al., 1997; ARAI et al., 2002a,b). Subsequently, misbalanced substrate/product ratio alters activity of other enzymes that finally can be observed as changes in the activity of several other enzymes as well as changes in their mutual ratio (aerobic oxidative versus anaerobic metabolism). Frequently glycolytic rate increases, more pyruvate goes into the Krebs cycle than into lactate. The availability of glucose-derived pyruvate for oxidative metabolism would mean less of a dependency on glutamine as a carbon source (Ross and MedinA 1998; Ross et al., 2000). Clearly, alterations in mitochondrial versus cytosolic enzyme activities and their ratio expressed as rate between aerobic oxidative and anaerobic metabolism can now be considered to be not only a good indicator of energy metabolism related to glucose utilization and aid in understanding of tumor metabolism but along with expression patterns of selected markers can also serve as potentially excellent diagnostic tools for the status, response to chemotherapy and prognosis of malignancy.

\section{Hormonal regulation of MDH functions}

Numerous studies in mammals and other vertebrates show that MDH activity can be co-operatively controlled by nutrients and hormones. Vertebrate $\mathrm{MDH}$ is a target for action of several hormones: catecholamines, insulin, thyroid hormone and retinoic acid (BALLARD and HANson 1967; GeER et al., 1976, 1980; Towle et al., 1980; DozIn et al., 1985; KNOPP and BRTKO 1987; MorioKa et al., 1989; HernANDEZ et al., 1993; MogENSEN et al., 2007). It is well known that in mammalian and avian models, thyroid hormone (ORTIZ-CARO and Jolin 1991; MoORADIAN et al., 1991; SALATI et al., 1991; MANn et al., 1992) and some steroids like estradiol (AsTIAZARAN et al., 1989; PATNAIK, 1990), androsterone (Song et al., 1989; MoHAn and CleARY, 1991) and nandrolone (TYLICKI et al., 2007) may stimulate activity of $\mathrm{MDH}$ by increasing $\mathrm{MDH}$ gene transcription and stabilizing MDH mRNA (Song et al., 1988; DESvERGNE et al., 1991). Thyroidal control of malate dehydrogenase, specifically cytosolic malic enzyme, activity and function is well documented phenomenon in higher vertebrates (FrenKel 1975; GoOdRIDGE 1975; BAGCHI et al., 
1986; GoODRIDGE et al., 1986, 1989, 1991, 1996; NIKODEM et al., 1989; IRITANI 1992). Moreover, rat MDH is positively regulated by both thyroid hormones and retinoids via their nuclear receptors recognizing specific response elements upstream of MDH promoter (MORIOKA et al., 1989; PETTY et al., 1990). In this case hormonal regulation crosstalks with factors of nutritional pathway to control lipogenesis at the level of malic enzyme that generates NADPH. Besides MDH and especially ME also additional enzymes such as glucose-6-phosphate dehydrogenase (G6PDH) and 6phosphogluconate dehydrogenase (6PGDH) can be upregulated by thyroid hormones (VARGHESE et al., 2001).

In chick embryo hepatocytes in culture, insulin and triiodothyronine (T3) were identified as positive effectors and glucagon, acting via cyclic AMP (cAMP), as a negative effector of ME activity. Hormone concentrations in blood are consistent with insulin and T3 playing the major positive roles, and glucagon a major negative endocrine role, in regulating hepatic malic enzyme activity during the transitions between the fed and the starved states. It was found that not only insulin but insulin-like growth factor 1 also stimulates accumulation of malic enzyme. Nutrition- and hormoneinduced changes in malic enzyme activity are due to altered concentrations of ME protein which, in turn, are due to altered rates of synthesis of ME. Synthesis of $\mathrm{ME}$ is controlled by regulating the level of $\mathrm{ME}$ mRNA which, in turn is regulated at initiation of transcription (GoODRIDGE et al., 1989).

Further experimental evidence obtained in mammals show that a low concentration of cAMP can act as a second messenger in a crosstalk between steroid hormones and retinoid acid resulting in the stimulation of MDH and ME (LAWRENCE and SALSGIVER 1984; YAMAGUCHI et al., 1999). In contrast, a higher concentration of cAMP can block the stimulation of ME gene expression by thyroid hormones on (SALATI et al., 1991; HERnANDEZ et al., 1993; Mounier et al., 1997). Finally, cAMP is known to be involved in mediating hysteretic response of several enzymes (MAGER 1976; JORDANA et al., 1984; Schiffmann 1989; Houge et al., 1990). Stimulation of ME activity can also be explained by a lipolytic action (SPIEGELMAN and GREen 1981). However, it is yet unknown whether such a mechanism is triggered by a hormonal signal.

It needs to be noted that $\mathrm{MDH}$ and/or ME response to various, notably hormonal, stimuli show two different phases. Insensitivity of the first short phase to RNA and protein synthesis indicates that during initial period (which may takes hours) of the response the activity of ME is increased most probably by recruiting or mobilizing of existing pools of the enzyme. Another possibility that cannot be ruled out is already mentioned hysteretic behaviour of ME which was described for many oxidoreductases including MDH and ME (SoulIE et al., 1988; Aon et al., 1989; CHERON et al., 1990; EdwARds and ANdreo 1992; Avilan and Garcia, 1994). Mobilization of existing pools of the enzyme can be achieved by several mechanisms including posttranslational modification or releasing enzyme protein from inactive state e.g. from interaction with chaperons etc.

Responsiveness of MDH or ME to hormonal stimuli is not always necessarily associated with lipogenesis, but rather it can reflect intensity of actual and sustaining demands of tissue specific energy metabolism. Thus, given the central role of the heart in responding to physiological changes and the high energy requirements of the myocardium, it is not surprising that cardiac myocytes are sensitive to the effects of thyroid hormone (RALPHE et al., 2004). Thyroid hormone acts on the heart through mechanisms that are both independent of and dependent on gene transcription. Acute effects seen early after exposure to the bioactive form of thyroid hormone, T3, include increases in heart rate, ejection fraction, and cardiac output, as well as increases in blood volume (KLEIN 1988). Important myocyte genes responsive to thyroid hormone that impact mechanical function have been identified, including $\alpha$-myosin heavy chain, sarcoplasmic reticulum $\mathrm{Ca}^{+}{ }^{+}$-ATPase, $\mathrm{Na}^{+}-\mathrm{K}^{+}$-ATPase, and several voltage-gated potassium channels (PANTos et al., 2004). Beyond its effects on cardiac mechanical function, thyroid hormone also directly impacts cardiac energetics and mitochondrial function. Thyroid hormone actions on mitochondria result from direct regulation of both nuclear and mitochondrial DNA transcription as well as from hemodynamic changes that indirectly alter gene expression (GoMBERG-MAITLAND and Frishman, 1998). Several nuclear-encoded respiratory chain genes have been identified that are induced after administration of T3, including cytochrome c1, cytochrome-c oxidase, F1ATP synthase subunit, glycero-3-phosphate dehydrogenase, and MDH (GoGLIA et al., 1999). In addition, the nuclear action of T3 on gene transcription, and energy metabolism can be further enhanced by facilitating mitochondrial protein import pathway including mitochondrial MDH (COLAVECCHIA et al., 2003 ). Control of energy metabolism by regulating mitochondrial 
MDH activity was found also in atypical situation associated with idiopathic pulmonary arterial hypertension (IPAH), a pathology related to low levels of the vasodilator nitric oxide (NO), that appears to be coregulated by insulin, thyroid and steroid hormones (XU et al., 2007).

Molecular mechanisms controlling hormonal response of $\mathrm{MDH} / \mathrm{ME}$ genes are of central interest for several years and it is still current issue as not all crucial questions were successfully answered. For example, in liver insulin stimulates the transcription of the gene encoding the cytosolic form of ME and modulates protein binding to two putative insulin response sequences (IRSs) in the ME promoter. One of these IRSs resembles that identified in the phosphoenolpyruvate carboxykinase (PEPCK) gene, whereas the other resembles that defined in the glyceraldehyde-3-phosphate dehydrogenase (GAPDH) gene. To assess the functional significance of these changes in protein binding, a series of truncated ME-chloramphenicol acetyltransferase (CAT) fusion genes were transiently transfected into rat H4IIE hepatoma cells. Deletion of the PEPCK-like IRS motif had no effect on the stimulation of CAT expression by insulin. Instead, the stimulatory effect of insulin was mediated through an AP-1 motif and an Egr-1 binding site that overlaps the GAPDH-like IRS motif. Both the ME AP-1 motif and the AP-1 motif identified in the collagenase-1 gene promoter were able to confer a stimulatory effect of insulin on the expression of a heterologous fusion gene, but surprisingly only the latter was able to confer a stimulatory effect of phorbol esters. Instead, the data suggest that AP-1 binds the ME AP-1 motif in an activated state such that phorbol ester treatment has no additional effect. The collagenase and ME AP-1 motifs were both shown to bind mainly Jun D and Fra-2, with similar affinities (STREEPER et al., 1998). In chick embryo hepatocytes, activation of ME gene transcription by $\mathrm{T} 3$ is mediated by a T3 response unit (T3RU) that contains five $\mathrm{T} 3$ response elements (T3REs) plus five accessory elements that enhance T3 responsiveness conferred by the T3REs. Results from in vitro binding assays indicate that one of the accessory elements (region F) binds CCAAT/enhancer-binding protein-alpha $(\mathrm{C} / \mathrm{EBP} \alpha)$. Transfection analyses demonstrated that the stimulation of T3RE function by region $\mathrm{F}$ did not require the presence of additional malic enzyme gene promoter sequences. Expression of a dominant negative C/EBP inhibited the ability of region $\mathrm{F}$ to stimulate $\mathrm{T} 3$ responsiveness. In chromatin immunoprecipi- tation assays, C/EBPalpha and TR associated with the malic enzyme T3RU in the absence and presence of $\mathrm{T} 3$ with the extent of the association being greater in the presence of $\mathrm{T} 3$. These observations indicate that $\mathrm{C} / \mathrm{EBPalph}$ interacts with TR on the malic enzyme T3RU to enhance T3 regulation of ME gene transcription. $\mathrm{T} 3$ treatment increased the acetylation of histones, decreased the recruitment of nuclear receptor corepressor and increased the recruitment of steroid receptor coactivator-1, CREB binding protein, and the thyroid hormone associated protein/mediator complex at the malic enzyme T3RU. In contrast, T3 treatment had no effect on the acetylation of histones and the recruitment of corepressors and coactivators at the T3RU that mediates the T3 activation of acetyl-CoA carboxylase$\alpha$ gene transcription (YIN et al., 2005). These observations indicate that ME activation by $\mathrm{T} 3$ can be, at least in part, $\mathrm{C} / \mathrm{EBP} \alpha$-dependent, although there are several other pathways that converge onto $\mathrm{C} / \mathrm{EBP} \alpha$ protein which is becoming an important crosstalk point. There is an evidence, that T3 transcription of ME in hepatocytes can be further enhanced by cooperative binding of chicken ovalbumin upstream-promoter transcription factor (COUP) and E-box-binding proteins to own enhancer within ME promoter (WANG et al., 2002). Recently a novel function has been assigned to Spot14 (S14) protein the expression of which has been found to be co-responsive with ME to T3 long time ago but leaving its biochemical function elusive (e.g. GoODRIDGE 1987). Experiments of CHOU et al. (2007) have shown that this small acidic protein forming homodimer is a nuclear factor that functionally interacts with thyroid hormone receptor (TR), a mediator of $\mathrm{T} 3$ action and can act as a positive or negative cofactor of the TR to regulate ME gene expression.

\section{Developmental aspects of MDH action and functions}

Although lipogenesis-prone or independent enzyme activity is continuous process during the life span of many eukaryotes, its intensity often displays developmental, cell cycle or ageing dependent variations. To study such developmentally-linked variations several model organisms have been used in which the activity of lipogenic enzymes including MDHs has been analyzed at biochemical or molecular level (BALlard and Hanson 1967; GeER et al., 1976; Towle et al., 1980; MoriokA et al. 1989). This indicates that regardless of lipogenesis MDH enzymes not only reflect ongoing changes in ontogenic phases but may play a specific role in ontogenic development. 
The procyclic forms of Trypanosoma brucei parasite possess three different malate dehydrogenases (mitochondrial, glycosomal and cytosolic). The latter is the only malate dehydrogenase expressed in the bloodstream forms, thus confirming that the expression of malate dehydrogenase isozymes is regulated during the T. brucei life cycle. Cloning followed by their expression in Escherichia coli cultures has revealed that mitochondrial malate dehydrogenase showed to be more active than glycosomal malate dehydrogenase in the reduction of oxaloacetate. Nearly $80 \%$ of the total activity in procyclic crude extracts corresponds to the former isozyme which also catalyzes, although less efficiently, the reduction of p-hydroxyphenyl-pyruvate. Importantly these studies helped to distinguish Trypanosoma brucei from Trypanosoma cruzi, since in the latter parasite a cytosolic malate dehydrogenase is not present and mitochondrial malate dehydrogenase specifically reduces oxaloacetate which can be very useful in diagnosis (ARANDA et al., 2006).

Quite surprisingly gene encoding malic enzyme (ME) in water arthropod, copepod Tigriopus californicus, appears to play role in separation of its two divergent populations (WILLETT and BERKOwITZ 2007). Comparison of cloned genes has shown that each ME gene has diverged extensively between $T$. californicus populations and one gene shows evidence for a recent selective sweep. Segregation patterns of genotypes for both ME genes in adult F2 hybrids reveal dramatic departures from Mendelian inheritance.

Some developmentally programmed changes in NAPDH-associated enzymes of rat liver including $\mathrm{MDH}$, succinate dehydrogenase, glutamate dehydrogenase, glucose-6-phosphate dehydrogenase can be reprogrammed during embryogenesis. In utero exposure to hydroxyprogesterone leads to significantly increased levels of these enzymes in adult male livers, while lactate dehydrogenase (LDH) activity was greatly reduced (PushPalatha et al., 2006). Simultaneously, activity of liver aminotransaminases, glutathione Stransferase and catalase were elevated. Even though these data could indicate that process of increased lipid peroxidation revealing some level of tissue damage and disruption of mitochondrial integrity could start, the tissue morphology appears normal. There is possibility that mentioned markers can mirror some portion of the protective detoxication pathway that has been switched on rather than whole damage machinery which could potentially lead to senescence. Therefore, observed changes can represent temporary reprogram- ming of gene expression while adverse conditions last. Another example when developmentally programmed expression of NADPH generating machinery and also glucose oxidation can be manipulated by exogenous administration of hormones is effect of excessive glucocorticoid on testicular testosterone production by Leydig cells. This treatment will cause significant decrease in rat ME, phosphogluconate dehydrogenase (6PGDH) and NADP-isocitrate dehydrogenase (ICDH) activity and lowered NADPH availability (KAVITHA et al., 2006). Cotreatment of rats with luteinizing hormone (LH) is capable of preventing 6-PGDH and ICDH decline but has no protective effect on ME activity and NADPH generation, thus leaving testosterone production at suppressed levels. Rescue of impaired glucose oxidation is not sufficient to protect Leydig cell steroidogenesis if defective NADPH generation remains defective. However, testosterone production can recover if excess corticosterone is removed.

Capacity of heart malate-aspartate shuttle (one of the NADH shuttles), which transfers cytosolic-reducing equivalents into the cardiac mitochondria, shows interesting developmental variations. Mitochondrial aspartate aminotransferase mRNA levels are greater in adult than in newborn myocardium. mRNA levels of mitochondrial malate dehydrogenase in adult cardiac tissue are 2.5-fold higher than in newborn tissue, whereas protein levels were $54 \%$ greater in adult myocardium. Aspartate/glutamate carrier protein levels are also greater in adult than in newborn tissue. mRNA and protein levels of the oxoglutarate/malate carrier are increased in newborn myocardium. These observations show that myocardial malate-aspartate shuttle capacity declines rapidly after birth, and indicate that divergence of mitochondrial MDH mRNA and protein levels during development could be due to posttranscriptional regulation of this protein (ScHOLZ et al., 1998). Results also suggest that developmental decline in malate-aspartate shuttle capacity appears to be regulated by decreased oxoglutarate/malate carrier gene expression. The malate/aspartate as well as $\alpha$-glycerophosphate shuttles show existence of sufficient capacity in cardiac mitochondria to accommodate increased shuttle flux even in hypertrophied myocardium that becomes more glycolytically active (RUPERT et al., 2000). However, elevated thyroid hormone leads to upregulation of metabolic pathways associated with energy production and development of heart hypertrophy, as observed by RALPHE et al. (2005). Expression of excitatory amino acid transporter type 1 (EAAT1) 
mRNA and protein that functions as a glutamate carrier in the malate/aspartate shuttle was increased nearly threefold in T3-treated animals, whereas expression of aralar1 and citrin (both cardiac mitochondrial aspartate-glutamate transporters) mRNA and protein levels remain decreased and unchanged, respectively. On the other hand, hypothyroidism resulted in a decrease in EAAT1 mRNA, but without any effect on the EAAT1 protein level or shuttle activity. This partially hormonal regulation of EAAT1 may facilitate increased metabolic demands of the cardiomyocyte during hyperthyroidism and impact cardiac function during development of hyperthyroidism.

Early neonatal and adult development of rat brain is accompanied by ontogenic changes in the cerebral pyruvate recycling pathway and the cellular localization of associated enzymes, ME and phosphoenolpyruvate carboxykinase (PEPCK). In contrast to gradually decreasing level of PEPCK, ME activity is steadily increasing to adult levels. Both enyzmes are expressed in astrocytes and in synaptosomes, but cortical neurons showed only PEPCK activity but no detectable ME activity (CRUZ et al., 1998). For developmentally-linked changes of human placental MDH activity is typical their variations related to levels of palmitoyl-CoA and oleate. As was shown by BANDYOPADHYAY et al. (1994) these changes can rather reflect modulating activity of fatty acid binding proteins (FABPs), an important mediator of fatty acid transport and action. Its function is rather peculiar as FABPs enhance the activity of malate dehydrogenase in absence of palmitoyl-CoA or oleate and also protect against palmitoyl-CoA or oleate inhibition. Ontogenic related MDH activity is detected throughout the gestation, showing a peak at midgestation, and it is anticipated that the modulatory effect of FABP may be due to the binding of long chain fatty acyl-CoA or fatty acid rather than a direct effect of FABPs on the enzyme.

Also development and capacitation of mammalian sperm are accompanied by expression of several marker proteins including MDH and isocitrate dehydrogenase (representatives of TCA cycle), and several other proteins like lactadherin $\mathrm{P} 47$, acrosomal protein SP-10 precursor, prohibitin, DJ-1 protein, arylsulfatase-A, and cytochrome c (CHOI et al., 2008). At least expression of cytochrome $\mathrm{c}$ appears to be regulated via p53 pathway and may be involved in decision developmentallylinked programmed cell death or further spermiogenesis. If developmental decision is switched towards apoptosis, MDH and isocitrate dehydrogenase are rapidly downregulated.
Besides above mentioned cases, there are additional non-lipogenic functions or unconventional roles of MDHs. Skeletal muscle development is accompanied by steadily but modestly increased levels of mitochondrial MDH, ATP synthase, succinate dehydrogenase, isocitrate dehydrogenase, pyruvate kinase, enolase and phosphofructokinase. Unexpectedly, in the process of ageing and under some pathological situations like sarcopenia, senescent muscular fibres show significantly increased levels of MDH, succinate dehydrogenase, $\mathrm{MDH}$, ATP synthase, succinate dehydrogenase, isocitrate dehydrogenase and isocitrate dehydrogenase, whereas pyruvate kinase, enolase and phosphofructokinase are apparently downregulated (DoRAn et al., 2008).

Some examples of MDH regulation and involvement in various processes described above may appear as episodic but gradually accumulating evidence from other model organisms, e.g. insects including Drosophila, provides more support for developmentallylinked role of malate dehydrogenases. In Drosophila melanogaster, several oxidative NADP-enzymes including cytosolic MDH (ME) have been extensively studied. It has been shown that activity of ME is low at the beginning of postembryonic development, gradually increases during larval life peaking in the first half of the last larval instar, is low during the pupal stage and freshly eclosed adults, then rises again with increasing age of adults (REDKIN 1970; CHERNIK et al., 1982; KAPLIN and KorOCHKIN, 1987; GEER et al., 1978a). The course of ME activity during larval development shows a strict pattern but it may be modulated by dietary factors. High saccharide diet results in increase of ME activity in feeding larvae while low saccharide/ high lipid diet makes ME activity drop to almost undetectable levels (GeER et al., 1976, 1978b, 1980; GEER and Perille 1977). Also, there is a tissue specific distribution of ME in Drosophila body with highest activity in larval fat body and a significant portion in larval imaginal discs (KuHN and SPREY 1987) and adult oviduct, ejaculatory duct and paragonia (FINKBOHNER et al., 1985). Later it was found that Drosophila ME is regulated by juvenile hormone $(\mathrm{JH})$ and $\mathrm{JH}$ analogues. However, the response of ME to JH depends on the developmental stage of the animal in relation to its endogenous titre of ecdysteroid hormones. During the interecdysial period of the last instar, when endogenous ecdysteroids are low, ME rapidly responded to $\mathrm{JH}$ by increasing activity, while little or no response was monitored in wandering (post-feeding) larvae, i.e., after a pulse of ecdysteroids. Activity of ME in ecdys- 
teroid-deficient mutants of Drosophila increased during a shift to restrictive temperature as compared to wild-type controls, and was sensitive to administration of JH. In contrast, when ecdysteroid-deficient mutants larvae during restrictive conditions were fed on a 20hydroxyecdysone diet, JH was unable to increase the activity of the ME enzyme. When JH was applied prior to 20-hydroxyecdysone feeding, the activity of ME was significantly stimulated. Two phases of ME response to $\mathrm{JH}$, dependent on ecdysteroids, could be observed. The first phase was short and independent of RNA and protein syntheses. But activation of ME in later stages of the response was inhibited by actinomycin $\mathrm{D}$ and cycloheximide, indicating that ME might be regulated by $\mathrm{JH}$ at the transcriptional and/or translational level (FARKAŠ and KNOPP, 1997). Another Drosophila mutant, $a p^{4}$ which is naturally deficient in $\mathrm{JH}$ production, displayed significantly reduced activity of $\mathrm{ME}$ in heterozygotic combination, and almost undetectable ME activity in null homozygote adults. The $a p^{4}$ phenotype was more strongly manifested in the adult stage than in larvae which showed 7-times lower requirements for $\mathrm{JH}$ titre. In addition, high/low sucrose diet fed to wild types or mutants affected the activity of larval ME, but the enzyme remained sensitive to administration of $\mathrm{JH}$. These results corroborate those described for mammals and provided the first evidence that Drosophila ME might be under differential hormonal and nutritional control (FARKAš and KNOPP, 1998). Further studies, also involving $e c d^{l}$ and $s u(f)^{t s 67 g}$ ecdysteroid-deficient mutations, revealed that response of $\mathrm{ME}$ to $\mathrm{JH}$ requires the presence of a minimal level of the steroid hormone ecdysone, showing a complex hormonal regulatory circuit in the execution of the $\mathrm{JH}$ response (FARKAš et al., 2002). Recently positive responsiveness of orthologous ME in a silkworm, Bombyx mori, to vertebrate steroid estradiol-17beta (E2) has been reported. The E2 has been described as one of vertebrate steroid hormones that have been identified in invertebrates, but without known function. E2-induced increase in fat body enzyme activity in 5th instar larval females could be counteracted by simultaneous application of specific E2-inhibitor, supporting possibility that E2 can have an important metabolic function (Roy et al., 2007). Molecular mechanisms of many of these responses mentioned above share common principles and therefore we can see clear links between their vertebrate and invertebrate counterparts. By using appropriate molecular-genetic tools and model organisms hopefully will not remain elusive for a long time.

\section{Acknowledgements}

Critical reading of the manuscript and helpfull editorial work of Denisa Liszeková and Milan Beňo are greatly appreciated. The work was supported by grants NSF IBN-97-24006-Suppl, and in part also by $2 / 7194 /$ 20, 2/3025/23 and 2/7102/27 from VEGA Slovakia, and APVT-51-027402 to R.F.

\section{References}

Aon MA, Cortassa S, Hervagault JF, Thomas D: pH-induced bistable dynamic behaviour in the reaction catalysed by glucose-6-phosphate dehydrogenase and conformational hysteresis of the enzyme. Biochem J 262, 795-800, 1989

Arai T, Ogawa T, Nakamura M, Hosoya M, Ohnishi Y: Changes in hepatic enzyme activities in transgenic mice carrying human prototype c-Ha-ras gene treated with diethylnitrosamine. J Vet Med Sci 64, 1065-1067, 2002a

Arai T, Ogawa T, Hosoya M, NaKamura M, Kawakami E: Changes in activities of enzymes related to energy metabolism in testicular tissues of dogs with seminoma. Vet Res Commun 26, 347-352, $2002 \mathrm{~b}$

Aranda A, Maugeri D, UtTaro AD, et al. The malate dehydrogenase isoforms from Trypanosoma brucei: subcellular localization and differential expression in bloodstream and procyclic forms. Int J Parasitol 36, 295-307, 2006

Ashton AR: NADP-malic enzyme from the C4 plant Flaveria bidentis: nucleotide substrate specificity. Arch Biochem Biophys 345, 251-258, 1997

Astiazaran AM, Chico Y, Ruiz MB, Alonso MS, Ochoa B, Lacort M: Metabolic changes due to the in vitro addition of estradiol in rat hepatocytes. Rev Esp Fisiol 45,19-24, 1989

Avilan L, Garcia P: Hysteresis of cytosolic NADP-malic enzyme II from Trypanosoma cruzi. Mol Biochem Parasitol 65, 225-232, 1994

Bagchi S, Wise LS, Brown ML, Sul HS, Bregman D, Rubin CS: Regulation and structure of murine malic enzyme mRNA. Ann NY Acad Sci 478, 77-92, 1986 
BAGGETTO LG: Deviant energetic metabolism of glycolytic cancer cells. Biochimie 74, 959-974, 1992.

Balinsky D, Platz CE, LEWIS JW: Isozyme patterns of normal, benign, and malignant human breast tissues. Cancer Res 43, 5895-5901, 1983

Balinsky D, Platz CE, LeWIs JW: Enzyme activities in normal, dysplastic, and cancerous human breast tissues. J Natl Cancer Inst 72, 217-224, 1984

BaLlaRd FJ, HANSON RW: Changes in lipid synthesis in rat liver during development. Biochem J 102, 952-958, 1967

Barroso I, SAntisteban P: Insulin-induced early growth response gene (Egr-1) mediates a short term repression of rat malic enzyme gene transcription. J Biol Chem 274 17997-18004, 1999

Brand K, Fekl W, von Hintzenstern J, Langer K, Luppa P, Schoerner C: Metabolism of glutamine in lymphocytes. Metabolism 38, 29-33, 1989

Caetano NN, Campello AP, Carnieri EG, Kluppel ML, Oliveira MB: Effect of methotrexate (MTX) on NAD(P)+ dehydrogenases of HeLa cells: malic enzyme, 2-oxoglutarate and isocitrate dehydrogenases. Cell Biochem Funct 15, 259-264, 1997

Chernik YI, Korytko OR, Belokon EM: (1982) Age changes of alcohol dehydrogenase, malate dehydrogenase and lactate dehydrogenase in Drosophila melanogaster. Ontogenez 13, 409-516, 1982

Cheron G, Noat G, Ricard J: Hysteresis of plant cell-wall beta-glucosidase. Biochem J 269, 389-392, 1990

Choi YJ, Uhm SJ, Song SJ, Song H, PARK JK, Kim T, PARK C, Kim JH: Cytochrome c upregulation during capacitation and spontaneous acrosome reaction determines the fate of pig sperm cells: linking proteome analysis. J Reprod Dev 54, 68-83, 2008

Chou WY, Cheng YS, Ho CL, Liu ST, et al.: Human spot 14 protein interacts physically and functionally with the thyroid receptor. Biochem Biophys Res Commun 357, 133-138, 2007

Colavecchia M, Christie LN, Kanwar YS, Hood DA: Functional consequences of thyroid hormone-induced changes in the mitochondrial protein import pathway. Am J Physiol Endocrinol Metab 284, E29-35, 2003

Cruz F, Scott SR, Barroso I, Santisteban P, Cerdan S: Ontogeny and cellular localization of the pyruvate recycling system in rat brain. J Neurochem 70, 2613-2619, 1998

Desvergne B, Petty KJ, Nikodem VM: Functional characterization and receptor binding studies of the malic enzyme thyroid hormone-response element. J Biol Chem 266, 1008-1013, 1991

Doran P, O’Connell K, Gannon J, Kavanagh M, Ohlendieck K: Opposite pathobiochemical fate of pyruvate kinase and adenylate kinase in aged rat skeletal muscle as revealed by proteomic DIGE analysis. Proteomics 8, 364-377, 2008

Dozin B, Magnuson MA, Nikodem VM: Tissue-specific regulation of two functional malic enzyme mRNAs by triiodothyronine. Biochemistry 24, 5581-5586, 1985

Drincovich MF, CASATi P, AndReo CS: NADP-malic enzyme from plants: a ubiquitous enzyme involved in different metabolic pathways. FEBS Lett 490, 1-6, 2001

Edwards GE, ANdreo CS: NADP-malic enzyme from plants. Phytochemistry 31, 1845-1857, 1992

EIgENBRODT E, Fister P, ReinACHER M: New perspectives on carbohydrate metabolism in tumor cells. In: Regulation of Carbohydrate Metabolism vol. II (Ed. R Beitner) pp. 141-179, CRC Press 1985

Eigenbrodt E, Reinacher M, Scheefers-Borchel U, Scheefers H, Fris R: Double role for pyruvate kinase type M2 in the expansion of phosphometabolite pools found in tumor cells Crit Rev Oncogenesis 3, 91-115, 1992

EsCHER CL, WIDMER F: Lipid mobilization and gluconeogenesis in plants: do glyoxalate cycle enzyme activities constitute a real cycle? A hypothesis. Biol Chem 378, 803-813, 1997

Farkaš R, Daniš P, Medved'ová L, Mechler BM, Knopp J: Regulation of cytosolic malate dehydrogenase by juvenile hormone in Drosophila melanogaster. Cell Biochem Biophys 37, 37-52, 2002

FARKAŠ R, KNOPP J: Ecdysone-modulated response of Drosophila cytosolic malate dehydrogenase to juvenile hormone. Arch Insect Biochem Physiol 35, 71-83, 1997

FARKAŠ R, KNOPP J: Genetic and hormonal control of cytosolic malate dehydrogenase activity in Drosophila melanogaster. Gen Physiol Biophys 17, 37-50, 1998

Finkbohner JD, Cunningham GN, Kuhn DT: Tissue distribution of malic enzyme-NADP in Drosophila melanogaster imaginal discs. Roux's Arch Dev Biol 194, 217-223, 1985

FRENKEL R: Regulation and physiological functions of malic enzymes. In: Current Topics in Cell Regulation vol. 9 (Eds. BL Horecker, ER Stadtman), pp. 157-181, Academic Press, New York, London 1975

GeEr BW, Kamiak SN, Kidd KR, Nishimura RA, Yemm SJ: Regulation of the oxidative NADP-enzyme tissue levels in Drosophila melanogaster. I. Modulation by dietary carbohydrate and lipid. J Exp Zool 195, 15-32, 1976 
Geer BW, Krochko D, Oliver MJ, Walker VK, Williamson JH: A comparative study of the NADP-malic enzymes from Drosophila and chick liver. Comp Biochem Physiol 65B, 25-34, 1980

GeER BW, PerIlle TJ: Effect of dietary sucrose and environmental temperature on fatty acid synthesis in Drosophila melanogaster. Insect Biochem 7, 371-379, 1977

Geer BW, Williamson JH, Oliver MJ, Walker VK, Bentley MM: The malic enzyme of Drosophila melanogaster. Can J Genet Cytol 20 Suppl, p. 444, 1978b

GeEr BW, Woodward CG, Marshall SD: Regulation of the oxidative NADP-enzyme tissue levels in Drosophila melanogaster. II. The biochemical basis of dietary carbohydrate and D-glycerate modulation. J Exp Zool 203, 391402, $1978 \mathrm{a}$

GiETL C: Malate dehydrogenase isoenzymes: cellular locations and role in the flow of metabolites between the cytoplasm and cell organelles. BBA 1100, 217-234, 1992a

GiETL C: Partitioning of malate dehydrogenase isoenzymes into glyoxysomes, mitochondria, and chloroplasts. Plant Physiol 100, 557-559, 1992b

Goglia F, Moreno M, Lanni A: Action of thyroid hormones at the cellular level: the mitochondrial target. FEBS Lett 452, 115-120, 1999

Gomberg-Maitland M, Frishman WH: Thyroid hormone and cardiovascular disease. Am Heart J 135, 187-196, 1998

Goodridge AG: Hormonal regulation of the activity of the fatty acid synthesizing system and of the malic enzyme concentration in liver cells-1,2. Fed Proc 34, 117-123, 1975

GoOdRIDGe AG: Dietary regulation of gene expression: enzymes involved in carbohydrate and lipid metabolism.Annu Rev Nutr 7, 157-185, 1987

Goodridge AG, Back DW, Wilson SB, Goldman MJ: Regulation of genes for enzymes involved in fatty acid synthesis. Ann NY Acad Sci 478, 46-62, 1986

Goodridge AG, Crish JF, Hillgartner FB, Wilson SB: Nutritional and hormonal regulation of the gene for avian malic enzyme. J Nutr 119, 299-308, 1989

Goodridge AG, Fantozzi DA, Klautky SA, Ma XJ, Roncero C, Salati LM: Nutritional and hormonal regulation of genes for lipogenic enzymes. Proc Nutr Soc 50, 115-122, 1991

Goodridge AG, Klautky SA, Fantozzi DA, et Al.: Nutritional and hormonal regulation of expression of the gene for malic enzyme. Prog Nucleic Acid Res Mol Biol 52, 89-122, 1996

Goward CR, Nicholls DJ: Malate dehydrogenase: a model for structure, evolution, and catalysis. Protein Sci 3, 18831888,1994

Hernandez A, Garcia-Jimenez C, Santisteban P, Obregon MJ: Regulation of malic enzyme gene expression by cAMP and retinoic acid in differentiating brown adipocytes. Eur J Biochem 215, 285-290, 1993

Hill S, Winning B, Jenner H, Knorpp C, Leaver C: Role of NAD(+)-dependent 'malic' enzyme and pyruvate dehydrogenase complex in leaf metabolism. Biochem Soc Trans 24, 743-746, 1996

Hock B, GiETL C: Cell-free synthesis of watermelon glyoxysomal malate dehydrogenase: a comparison with the mitochondrial isoenzyme. Ann NY Acad Sci 386, 350-376, 1982

Houge G, Vintermyr OK, Doskeland SO: The expression of cAMP-dependent protein kinase subunits in primary rat hepatocyte cultures. Cyclic AMP down-regulates its own effector system by decreasing the amount of catalytic subunit and increasing the mRNAs for the inhibitory $(\mathrm{R})$ subunits of cAMP-dependent protein kinase. Mol Endocrinol 4, 481-488, 1990

IRITANI N: Nutritional and hormonal regulation of lipogenic-enzyme gene expression in rat liver. Eur J Biochem 205, 433-442, 1992

Jordana X, Olate J, Allende CC, Allende JE: Studies on the mechanism of inhibition of amphibian oocyte adenylate cyclase by progesterone. Arch Biochem Biophys 228, 379-387, 1984

KAPLIN VS, KoROCHKIN LI: A histochemical and microelectrophoretical study of esterases in the organs and tissues of Drosophila melanogaster during embryo- and larvogenesis. 3. Alcohol and malate dehydrogenases. Ontogenez 18, 215-220, 1987

Kavitha TS, Parthasarathy C, Sivakumar R, ET Al.: Effects of excess corticosterone on NADPH generating enzymes and glucose oxidation in Leydig cells of adult rats. Hum Exp Toxicol 25, 119-125, 2006

KLEIN I: Thyroxine-induced cardiac hypertrophy: time course of development and inhibition by propanolol. Endocrinology 123, 203-210, 1988

KNOPP J, BRTKo J: Effect of thyroxine in vivo on malic enzyme activity in liver cytosol of propylthiouracil and alphaamanitin treated rats. Endocrinol Exper 21, 125-132, 1987 
KuHN DT, SPREY TE: Regulation of NADP-malic enzyme in the eye-antennal disc of D. melanogaster/D. simulans hybrids: evidence for cis- and trans-regulation. Genetics 115, 277-281, 1987

LAWRENCE JC JR, SALSGIVER WJ: Evidence that levels of malate dehydrogenase and fumarase are increased by cAMP in rat myotubes. Am J Physiol 247, C33-38, 1984

Lo AS, LiEw CT, NGaI SM, ET AL.: Developmental regulation and cellular distribution of human cytosolic malate dehydrogenase (MDH1). J Cell Biochem 94, 763-773, 2005

LoEber G, Dworkin MB, INFANTe A, AHorn H: Characterization of cytosolic malic enzyme in human tumor cells. FEBS Lett 344, 181-186, 1994

Loeber G, Infante AA, Maurer-Fogy I, et Al.: Human NAD(+)-dependent mitochondrial malic enzyme. cDNA cloning, primary structure, and expression in Escherichia coli. J Biol Chem 266, 3016-3021, 1991

MAGER PP: Hysteresis at an electrochemical membrane model and its possible role in circulation research. Arzneimittelforschung 26, 1818-1819, 1976

MANn DJ, StRAin AJ, Bailey E: Hormonal induction of malic enzyme in rat hepatocytes cultured on laminin-rich gels. J Mol Endocrinol 8, 235-242, 1992

MaRhuenda-Egea FC, Bonete MJ: Extreme halophilic enzymes in organic solvents. Curr Opin Biotechnol 13, 385-389, 2002

Mazurek S, Eigenbrodt E, Failing K, Steinberg P: Alterations in the glycolytic and glutaminolytic pathways after malignant transformation of rat liver oval cells. J Cell Physiol 181, 136-146, 1999

Mazurek S, Grimm H, Wilker S, Leib S, Eigenbrodt E: Metabolic characteristics of different malignant cancer cell lines. Anticancer Res 18, 3275-3282, 1998

Mazurek S, Hugo F, Failing K, Eigenbrodt E: Studies on associations of glycolytic and glutaminolytic enzymes in MCF-7 cells: role of P36. J Cell Physiol 167, 238-250, 1996

McAlister-Henn L, Small WC: Molecular genetics of yeast TCA cycle isozymes. Prog Nucleic Acid Res Mol Biol 57, 317-339, 1997

McKeenan WL: Glycolysis, glutaminolysis and cell proliferation. Cell Biol Int Rep 6, 635-647, 1982

Mevarech M, Frolow F, Gloss LM: Halophilic enzymes: proteins with a grain of salt. Biophys Chem 86, 155-164, 2000

Minarik P, Tomaskova N, Kollarova M, Antalik M: Malate dehydrogenases - structure and function. Gen Physiol Biophys 21, 257-265, 2002

Mogensen M, Sahlin K, Fernström M, et AL.: Mitochondrial respiration is decreased in skeletal muscle of patients with type 2 diabetes. Diabetes 56, 1592-1599, 2007

Mohan PF, CleARY MP: Short-term effects of dehydroepiandrosterone treatment in rats on mitochondrial respiration. J Nutr 121, 240-250, 1991

Mooradian AD, DeEbaj L, Wong NC: Age-related alterations in the response of hepatic lipogenic enzymes to altered thyroid states in the rat. J Endocrinol 128, 79-84, 1991

Morioka H, Magnuson MA, Mitshuhashi T, Song MKH, Rall JE, Nikodem VM: Structural characterization of rat malic enzyme gene. Proc Natl Acad Sci USA 86, 4912-4916, 1989

Mounier C, Chen W, Klautky SA, Goodridge AG: Cyclic AMP-mediated inhibition of transcription of the malic enzyme gene in chick embryo hepatocytes in culture. Characterization of a cis-acting element far upstream of the promoter. J Biol Chem 272, 23606-23615, 1997

Musrati Ra, Kollarova M, Mernik N, Mikulasova D: Malate dehydrogenase: distribution, function and properties. Gen Physiol Biophys 17, 193-210, 1998

Nikodem VM, Magnuson MA, Dozin B, Morioka H: Coding nucleotide sequence of rat malic enzyme mRNA and tissue specific regulation by thyroid hormone. Endocr Res 15, 547-564, 1989

Noguchi Y, Vydelingum NA, BRennan MF: Tumor-induced alterations in hepatic malic enzyme and carnitine palmitoyltransferase activity. J Surg Res 55, 357-363, 1993

Ortiz-Caro J, Jolin T: Triiodothyronine and insulin effects on malic enzyme in hypothyroid and diabetic rats. Acta Endocrinol Copenh 124, 569-576, 1991

Pantos C, Malliopoulou V, Varonos DD, Cokrinos DV: Thyroid hormone and phenotypes of cardioprotection. Basic Res Cardiol 99, 101-120, 2004

PATNAIK SK: Differential regulation of malate dehydrogenase isoenzymes by estradiol in the brain of rats and various ages. Biochem Int 20, 633-639, 1990

Perumal SS, Shanthi P, Sachdanandam P: Therapeutic effect of tamoxifen and energy-modulating vitamins on carbohydrate-metabolizing enzymes in breast cancer. Cancer Chemother Pharmacol 56, 105-114, 2005 
Petty KJ, Desvergne B, Mitsuhashi T, Nikodem VM: Identification of a thyroid hormone response element in the malic enzyme gene. J Biol Chem 265, 7395-7400, 1990

Povey S, Jeremiah S, Arthur E, Ber R, et al.: Deficiency of malic enzyme: a possible marker for malignancy in lymphoid cells. Ann Hum Genet 45, 237-252, 1981

PushPAlATHA T, REDDY PR, REDDY PS: Alterations in hepatic metabolism of adult male rats following exposure to hydroxyprogesterone during embryonic development. Asian J Androl 8, 463-467, 2006

RALPHE JC, BEDEll K, SEgAR JL, Scholz TD: Correlation between myocardial malate/aspartate shuttle activity and EAAT1 protein expression in hyper- and hypothyroidism. Am J Physiol Heart Circ Physiol 288, H2521-H2526, 2005

Rao KN, Elm MS, Kelly RH, Chandar N,ET AL.: Hepatic hyperplasia and cancer in rats: metabolic alterations associated with cell growth. Gastroenterology 113, 238-248, 1997

REDKIN PS: Dynamics of the activity of isozymes of malate dehydrogenase in ontogenesis of Drosophila virilis. Soviet J Devel Biol 1, 89-94, 1970

Ross CD, GomaA MA, Gillies E, Juengel R, Medina JE: Tumor grade, microvessel density, and activities of malate dehydrogenase, lactate dehydrogenase, and hexokinase in squamous cell carcinoma. Otolaryngol Head Neck Surg 122, 195-200, 2000

Ross CD, Medina JE: Quantitative biochemical analysis of samples from squamous cell carcinoma. Otolaryngol Head Neck Surg 119, 455-459, 1998

Roy S, De J, Kundu S, Biswas A,ET AL.: Estradiol-17beta: tracing its metabolic significance in female fatbody of fifth instar larvae of silkworm, Bombyx mori L (race: Nistari). Life Sci 80, 446-453, 2007

Rupert BE, Segar JL, Schutte BC, Scholz TD: Metabolic adaptation of the hypertrophied heart: role of the malate/ aspartate and alpha-glycerophosphate shuttles. J Mol Cell Cardiol 32, 2287-2297, 2000

Salati LM, Ma XJ, McCormick CC, Stapleton SR, Goodridge AG: Triiodothyronine stimulates and cyclic AMP inhibits transcription of the gene for malic enzyme in chick embryo hepatocytes in culture. J Biol Chem 266, 40104016, 1991

SAUER LA, DAUChY RT: Identification and properties of the nicotinamide adenine dinucleotide (phosphate)+-dependent malic enzyme in mouse ascites tumor mitochondria. Cancer Res 38, 1751-1756, 1978

Sauer LA, Dauchy RT, Nagel WO, Morris HP: Mitochondrial malic enzymes. Mitochondrial NAD(P)+-dependent malic enzyme activity and malate-dependent pyruvate formation are progression-linked in Morris hepatomas. J Biol Chem 255, 3844-3848, 1980

SChIFFMANN Y: Bistability and control for ATP synthase and adenylate cyclase is obtained by the removal of substrate inhibition. Mol Cell Biochem 86, 19-40, 1989

Scholz TD, Koppenhafer SL, TENEyck CJ, Schutte BC: Ontogeny of malate-aspartate shuttle capacity and gene expression in cardiac mitochondria. Am J Physiol 274, C780-788, 1998

Song MK, Dozin B, Grieco D, Rall JE, Nikodem VM: Transcriptional activation and stabilization of malic enzyme mRNA precursor by thyroid hormone. J Biol Chem 263, 17070-17974, 1988

Song MK, Grieco D, Rall JE, Nikodem VM: Thyroid hormone mediated transcriptional activation of rat liver malic enzyme gene by dehydroepiandrosterone. J Biol Chem 264, 18981-18985, 1989

SOUlie J-M, RiviERE M, RicARD J: Enzymes as biosensors. 2: Hysteretic response of chloroplastic fructose-1,6-biphosphatase to fructose-2,6-biphosphate. Eur J Biochem 176, 111-117, 1988

SPIEGELMAN BM, GREEN H: Cyclic AMP-mediated control of lipogenic enzyme synthesis during adipose differentiation of 3 T3 cells. Cell 24, 503-510, 1981

Streeper RS, Chapman SC, Ayala Je, Svitek CA, Goldman JK, Cave A, O’Brien RM: A phorbol ester-insensitive AP1 motif mediates the stimulatory effect of insulin on rat malic enzyme gene transcription. Mol Endocrinol 12, 1778-1791, 1998

Tehei M, Zaccai G: Adaptation to extreme environments: macromolecular dynamics in complex systems. Biochim Biophys Acta 1724, 404-410, 2005

Towle HC, MARIASH CN, OppenheIMER JH: Changes in the hepatic levels of messenger ribonucleic acid for malic enzyme during induction by thyroid hormone or diet. Biochemistry 19, 579-585, 1980

Tripathi G: A review on molecular physiology of malate and lactate dehydrogenases in fishes. Biomed Environ Sci 6, 286-318, 1993

Tylicki A, Kawalko A, Sokolska J, Strumilo S: Effect of anabolic steroid nandrolone decanoate on the properties of certain enzymes in the heart, liver, and muscle of rats, and their effect on rats' cardiac electrophysiology. Horm Metab Res 39, 268-272, 2007 
Varghese S, Shameena B, Sudhakaran PR, Oommen OV: Short-term effects of thyroid hormones on lipogenic enzymes and 14C-acetate incorporation into various lipid classes: in vivo and in vitro studies. Indian J Exp Biol 39, 431435, 2001

Wang Y, Zhang Y, Hillgartner FB: Chicken ovalbumin upstream-promoter transcription factor and E-box-binding proteins enhance thyroid-hormone responsiveness of the malic enzyme gene in avian hepatocytes. Biochem J 361, 391-400, 2002

Washizu T, Azakami D, Bonkobara M, Washizu M, Arai T: Changes in activities of enzymes related to energy metabolism in canine lymphoma cells. J Vet Med Sci 67, 615-616, 2005

WASILENKo WJ, MARChOK AC: Malic enzyme and malate dehydrogenase activities in rat tracheal epithelial cells during the progression of neoplasia. Cancer Lett 28, 35-42, 1985

WILLETT CS, BERKOwITZ JN: Viability effects and not meoitic drive cause dramatic departures from Mendelian inheritance for malic enzyme in hybrids of Tigriopus californicus populations. J Evol Biol 20, 1196-1205, 2007

Xu W, KOECK T, LARA AR, NEUMANN D,ET AL.: Alterations of cellular bioenergetics in pulmonary artery endothelial cells. Proc Natl Acad Sci USA 104, 1342-1347, 2007

Yamaguchi S, Murata Y, Nagaya T, Hayashi Y, Ohmori S, Nimura Y, Seo H: Glucocorticoids increase retinoid-X receptor alpha expression and enhance thyroid hormone action in primary cultured rat hepatocytes. J Mol Endocrinol 22, 81-90, 1999

Yin L, WANG Y, DRIDI S, Vinson C, HiLlgartner FB: Role of CCAAT/enhancer-binding protein, histone acetylation, and coactivator recruitment in the regulation of malic enzyme transcription by thyroid hormone. Molec Cell Endocrinol 245, 43-52, 2005

Yoon SJ, Koo DB, Park JS, Cho KH, Han YM, Lee KA: Role of cytosolic malate dehydrogenase in oocyte maturation and embryo development. Fertil Steril 86, 1129-1136, 2006 